\title{
A small proline-rich protein (SPRR) gene variant contributes to atopic eczema and eczema-associated asthma susceptibility
}

\author{
Anna Dębińska', Hanna Danielewicz ${ }^{1}$ Andrzej Boznański ${ }^{1}$, Łukasz Matusiak², Jacek C. Szepietowski² \\ ${ }^{1} 1^{\text {st }}$ Department and Clinic of Paediatrics, Allergology and Cardiology, Wroclaw Medical University, Wroclaw, Poland
} ${ }^{2}$ Department of Dermatology, Venerology and Allergology, Wroclaw Medical University, Wroclaw, Poland

Adv Dermatol Allergol 2022; XXXIX (5): 965-971 DOI: https://doi.org/10.5114/ada.2022.113145

\begin{abstract}
Introduction: There is some evidence that genetic variants in the epidermal differentiation complex (EDC) genes on chromosome 1q21 may be involved in the pathogenesis of atopic eczema (AE) similar to the well-known filaggrin gene (FLG) mutations.

Aim: To evaluate the association of SNP in the small proline-rich protein 2B (SPRR2B) gene with atopic eczema and other allergic phenotypes and to investigate its possible interaction with FLG mutations.

Material and methods: One hundred and eighty-eight children less than 2 years old were screened for the variant of allele rs6693927 in the SPRR2B gene and for 4 most prevalent FLG mutations. The variant of allele rs6693927 and all FLG mutations were genotyped by real-time polymerase chain reaction assays with subsequent melting curve analysis using SimpleProbe ${ }^{\oplus}$ probes.

Results: The allele rs6693927[A] was associated with a significantly increased risk of AE (OR = 3.02; 95\% Cl: 1.17-8.00; $p=0.011)$ and the effect was independent of FLG risk alleles. The largest effects were observed in patients with a combined asthma-plus-eczema phenotype (OR $=5.44 ; 95 \% \mathrm{Cl}: 1.17-25.16 ; p=0.029)$. Finally, in eczema, we found interactions of rs6693927[A] with FLG mutations, the risk of eczema was the most increased in the subjects who combined both rs6693927[A] allele and FLG mutations.

Conclusions: The SPRR2B risk variant may play an important role in the development of atopic eczema and the particular eczema-associated asthma phenotype in young children. The effect seems to be independent of, and supplementary to, the well-known FLG mutations and may be modulated by gene-gene interactions.
\end{abstract}

Key words: atopic eczema, epidermal differentiation complex, filaggrin, SNP.

\section{Introduction}

Atopic eczema (AE) is the most common chronic inflammatory skin disease frequently associated with other diseases of the atopic diathesis [1]. AE is often considered the window to development of other atopic manifestations, including asthma and allergic rhinitis [2-4]. A multifactorial background for AE has been suggested with genetic as well as environmental factors influencing disease development $[5,6]$. Several metaanalyses have confirmed a strong association of the filaggrin (FLG) null mutations with AE and other allergic diseases, especially asthma occurring in association with eczema [7-13]. These results have highlighted that genetically determined impairment of the skin barrier is critical not only for the development of AE, but also for other allergic disorders [14-19]. The evidence from both expression studies and Genome-Wide Association Studies (GWASs) suggest that numerous other genes essential for maintaining the skin barrier are located within the epidermal differentiation complex (EDC), a region on chromosome 1q21, and may be involved in the pathogenesis of $A E$ and progression to secondary allergies similar to the well-known FLG mutations [20-24].

Small proline-rich proteins (SPRRs) encoded on the 1 q21 region function as cross-bridging proteins of the cornified envelope (CE) that provides the main barrier function of the skin [25]. Experimental studies have pro-

Address for correspondence: Prof. Jacek C. Szepietowski MD, PhD, Department of Dermatology, Venerology and Allergology, Wroclaw Medical University, 1 T. Chałubińskiego St, 50-368 Wroclaw, Poland, phone: +48 601534 853, e-mail: jacek.szepietowski@umed.wroc.pl Received: 11.09.2021, accepted: 19.12.2021. 
vided data indicating the altered pattern in SPRR protein expression in AE skin lesions and also in a mouse model of asthma $[22,26]$. This finding suggests that the SPRR gene may be associated not only with $A E$, but also with asthma [27-29]. We focused on polymorphisms in the SPRR2 gene because SPRR2 proteins have been shown to be allergen- and IL-13-induced gene products that may be involved in the pathophysiology of allergic responses in diverse mucosal tissues [26].

\section{Aim}

In the current study, we aimed to determine the importance of the rs6693927 polymorphism in the SPRR2B gene in the susceptibility to childhood AE and other atopic phenotypes such as eczema-associated asthma. Moreover, we evaluated whether this possible association is independent of the well-described FLG risk alleles.

\section{Material and methods}

\section{Study population}

A total of 188 unrelated children (107 males) less than 2 years old at the time of recruitment were enrolled; namely, 103 patients with AE (mean age: $13.2 \pm 6.7$ months) and 85 healthy control subjects (mean age: $15.3 \pm 5.6$ months). The whole study population were followed at yearly intervals until the age of 6 years. All study participants were of Caucasian ethnicity. The study subjects were recruited from patients who visited the Outpatient Clinic for Children at the Wroclaw Medical University Hospital and from the general population, as described below. The healthy control subjects were recruited from the general population through community-based approaches. We distributed flyers at local nurseries, child and family doctors' surgeries, health fairs. Interested parents were instructed to contact the research coordinator by telephone. All participants, cases and controls, were selected using a detailed questionnaire that included questions regarding the overall health status, symptoms of $A E$ and other allergic diseases, sociodemographic information and family history of allergic diseases. The subjects with AE were examined and diagnosed according to the criteria established by Hanifin and Rajka [30]. The mean age at disease onset was $4.6 \pm 3.5$ months. AE disease severity was assessed by using the SCORing Atopic Dermatitis (SCORAD) index. Subjects with AE were divided into allergic and non-allergic on the basis of the positive specific IgE level against at least one of the allergens tested. Asthma was defined by the presence of one or more wheezing episodes during the previous 12 months at the age 5 and/or 6 years or a physician's diagnosis of asthma by 6 years of age. Allergic rhinitis was defined by a physician's diagnosis of allergic rhinitis by 6 years of age. The control group included healthy children and met the following criteria: absence of symp- toms of AE and asthma or allergic rhinitis and negative family history of allergic diseases.

Serum measurements for total and specific IgE levels were performed in all recruited subjects, including IgE specific to the most popular 10 inhalant and 10 food allergens. The levels of specific IgE were determined using a standard enzyme immunoassay (Polycheck, BIOCHECK, Germany). Allergic sensitisation was defined as the presence of a specific IgE to at least one of the tested allergens of $\geq 0.7 \mathrm{kU} / \mathrm{l}$ (Class II).

The study was approved by the Ethics Committee of the Wroclaw Medical University, Wroclaw, Poland and informed written consent, including consent to genetic studies, was obtained from all of the subjects before testing.

\section{Genotyping}

Samples of the 188 subjects were genotyped for the SPRR2B rs6693927 SNP and for the four common FLG mutations: R501X, 2282del4, R2447X and S3247X on chromosome 1 q21 as described previously [31, 32]. Genomic DNA was obtained from EDTA whole blood samples using the QIAamp DNA Blood Mini Kit (QIAGEN GmbH, Germany). All mutations were determined using a LightSNiP assay (TIB Molbiol, Berlin, Germany). PCR was performed in a final volume of $10 \mu \mathrm{l}$ containing $1 \mu \mathrm{l}$ of DNA at concentration $15-60 \mathrm{ng} / \mu \mathrm{l}, 0.5 \mu \mathrm{l}$ of reagent mix containing specific primers and SimpleProbe ${ }^{\oplus}$ probes at optimised concentration, $0.8 \mu \mathrm{l}$ of $\mathrm{MgCl}_{2}$ and $1 \mu \mathrm{l}$ of LightCycler ${ }^{\oplus}$ FastStart DNA Master HybProbe (Roche Applied Science, Mannheim, Germany). Reactions were performed on a LightCycler 1.5 platform (Roche Applied Science, Mannheim, Germany). For quality control of genotyping procedures, positive controls of each genotype, as well as negative controls, were included in each reaction.

\section{Statistical analysis}

The Hardy-Weinberg equilibrium was tested using the $\chi^{2}$ goodness-of-fit test to compare observed genotype frequencies with expected frequencies among the controls. Differences in genotype frequencies or demographic characteristics between case and control groups were evaluated using the $\chi^{2}$ test or Fisher exact test, as appropriate. The associations of genotypes or alleles with patient groups versus control subjects were determined by computing the odds ratio (OR), its $95 \%$ confidence interval $(95 \% \mathrm{Cl})$ and $p$-values, using logistic regression analysis for crude ORs and adjusted ORs when adjusting for family history of atopy. Statistical significance was set at $p<0.05$. A $\chi^{2}$ test or Fisher exact test was used to determine the combined effect of genotype pairs. Gene-gene interaction was investigated by using logistic regression models for atopic AE with interaction terms (SPSS). To establish whether an interaction between the two risk factors A (rs6693927) and B (FLG mutations) 
existed, the relative excess risk due to interaction (RERI), the proportion attributable to interaction (AP), the synergy index (S) and the ratio of ORs were calculated, as recommended by Knoll et al. [33, 34]. Statistical analysis was carried out using the program package Statistica Version 9.0 (StatSoft, Inc., Tulsa, OK, USA) and the SPSS Statistics software package Version 11.1 (SPSS Inc., Chicago, IL, USA).

\section{Results}

Baseline characteristics of patients with AE and controls are given in Table 1. There were no significant differences between the cases and controls for age and gender. The allele and genotype distributions for the SPRR2B rs6693927 SNP in the cases and controls are shown in Table 2.

In the overall study population, the rs6693927 polymorphism of the SPRR2B gene did not significantly increase the risk of $A E$; however, there was a trend towards an association of the risk allele A and AE. Moreover, after stratification for allergic and non-allergic $A E$ groups, we found a highly significant association of SNP rs6693927 with AE but only in the non-allergic group. In the logistic regression analysis in the non-allergic group, the rs6693927 AA homozygote and AG heterozygote were associated with a significantly increased risk of $A E$ compared to the wild-type homozygote. The genotype model showed an OR of 2.93 for heterozygote individuals and 3.50 for homozygotes. The OR associated with the rs6693927 SNP was estimated at 1.71, using the allele model (Table 2). The non-allergic and allergic AE groups did not differ in terms of frequency of rs6693927 SNP $\left(p=0.156 ; \chi^{2}=3.710\right)$.

There were no significant associations between $A E$ severity and the SPRR2B rs6693927 SNP. The mild and moderate $A E$ groups did not differ in terms of frequency of SPRR2B rs6693927 SNP ( $p=0.971 ; \chi^{2}=0.595$; data not shown).
Next, we investigated whether the association of rs6693927 SNP with AE is affected by the strongly significant FLG null mutation status. We therefore included the combined FLG genotype as a second predictor in a logistic regression model to determine whether the FLG mutations confound rs6693927 SNP and AE association in the non-allergic group. After adjusting for the presence of FLG mutations the rs6693927 SNP still showed a statistically significant effect $(p=0.011)$ with an OR of 3.12 (95\% Cl: 1.28-7.59). Moreover, we investigated whether an interaction between rs6693927 SNP and the four most common FLG mutations influenced the AE risk. Compared to the reference group carrying neither genetic risk factor, a strong effect was revealed only in subjects who carried both risk factors; the presence of at least one rs6693927 [A] allele and at least one loss-of-function FLG mutation significantly increased the AE risk (Table 3). Figure 1 shows this graphically. Our results suggest that there is some evidence of a gene-gene interaction on additive and multiplicative scales, although when modelling interaction, the interaction coefficient was not significant for both genotype combinations ( $p$-value for interaction

Table 1. Characteristics of the study group

\begin{tabular}{lcc}
\hline Variable & $\begin{array}{c}\text { Atopic eczema } \\
n=103\end{array}$ & $\begin{array}{c}\text { Control } \\
n=85\end{array}$ \\
\hline Age [month] (mean \pm SD) & $13.6 \pm 6.7$ & $15.9 \pm 5.6$ \\
\hline Gender (male/female) & $63 / 40$ & $44 / 41$ \\
\hline Allergic sensitisation (\%) & $55(53.4 \%)$ & $11(12.9 \%)$ \\
\hline SCORAD: & & \\
\hline Mild & $79(76.7 \%)$ & 0 \\
\hline Moderate & $24(23.3 \%)$ & 0 \\
\hline Severe & 0 & 0 \\
\hline Atopic hereditary $(\%)$ & $57(55.3 \%)$ & 0 \\
\hline Serum total IgE [IU/ml] & 24.6 & 17.7 \\
geometric mean, $95 \% \mathrm{Cl}$ & $(27.8-53.4)$ & $(14.3-22.2)$ \\
\hline
\end{tabular}

Table 2. Genotype and allele frequencies of SPRR2B rs6693927 in the group studied

\begin{tabular}{|c|c|c|c|c|c|c|c|c|c|c|}
\hline \multirow[t]{2}{*}{ Genotype } & \multirow{2}{*}{$\begin{array}{c}\text { Control } \\
n(\%)\end{array}$} & \multicolumn{3}{|c|}{ Atopic eczema } & \multicolumn{3}{|c|}{ Allergic atopic eczema } & \multicolumn{3}{|c|}{ Non-allergic atopic eczema } \\
\hline & & $n(\%)$ & $P$-value & $\begin{array}{c}\mathrm{aOR}^{*} \\
(95 \% \mathrm{Cl})\end{array}$ & $n(\%)$ & $P$-value & $\begin{array}{c}\mathrm{aOR}^{*} \\
(95 \% \mathrm{Cl})\end{array}$ & $n(\%)$ & $P$-value & $\begin{array}{c}\mathrm{aOR}^{*} \\
(95 \% \mathrm{Cl})\end{array}$ \\
\hline \multicolumn{11}{|c|}{ SPRR2B rs6693927 } \\
\hline GG & $32(38 \%)$ & $26(25 \%)$ & 0.152 & 1.00 (Reference) & $18(33 \%)$ & 0.608 & 1.00 (Reference) & $8(17 \%)$ & 0.038 & $\begin{array}{c}1.00 \\
\text { (Reference) }\end{array}$ \\
\hline$A G$ & $45(53 \%)$ & $62(60 \%)$ & & $1.69(0.84-3.40)$ & $29(53 \%)$ & & $1.14(0.51-2.57)$ & $33(69 \%)$ & & $2.93(1.11-7.95)$ \\
\hline AA & $8(9 \%)$ & $15(15 \%)$ & & $2.31(0.76-7.11)$ & $8(16 \%)$ & & $1.78(0.49-6.42)$ & 7 (15\%) & & $3.50(0.82-15.3)$ \\
\hline$A G+A A$ & $53(62 \%)$ & $77(75 \%)$ & 0.067 & $1.78(0.91-3.50)$ & $37(67 \%)$ & 0.553 & $1.24(0.57-2.69)$ & $40(83 \%)$ & 0.011 & $3.02(1.17-8.00)$ \\
\hline$A$ & $61(36 \%)$ & $92(44 \%)$ & 0.085 & $1.44(0.93-2.23)$ & 45 (41\%) & 0.397 & $1.23(0.73-2.08)$ & $47(49 \%)$ & 0.037 & $1.71(0.99-2.94)$ \\
\hline
\end{tabular}

*Adjusted odds ratio (aOR) by family history of atopy. 
Table 3. Interaction between SPRR2B rs6693927 and the FLG mutations in atopic eczema

\begin{tabular}{|c|c|c|c|c|c|}
\hline Genotype combinations & $\begin{array}{c}\text { Atopic eczema } \\
n(\%)\end{array}$ & $\begin{array}{c}\text { Control } \\
n(\%)\end{array}$ & $P$-value & OR $(95 \% \mathrm{Cl})$ & $\operatorname{RR}(95 \% \mathrm{Cl})$ \\
\hline $\begin{array}{l}\text { FLG mutation (-) } \\
\text { rs6693927 GG }\end{array}$ & $\begin{array}{c}24 \\
(23.3 \%)\end{array}$ & $\begin{array}{c}31 \\
(36.4 \%)\end{array}$ & & $\begin{array}{c}1.00 \text { (ref.) } \\
-\end{array}$ & $\begin{array}{c}1.00 \text { (ref.) } \\
-\end{array}$ \\
\hline $\begin{array}{l}\text { FLG mutation (-) } \\
\text { rs6693927 AG+AA }\end{array}$ & $\begin{array}{c}65 \\
(63.1 \%)\end{array}$ & $\begin{array}{c}52 \\
(61.2 \%)\end{array}$ & 0.145 & $\begin{array}{c}1.61 \\
(0.80-3.24)\end{array}$ & $\begin{array}{c}1.27 \\
(0.90-1.87)\end{array}$ \\
\hline $\begin{array}{l}\text { FLG mutation (+) } \\
\text { rs6693927 GG }\end{array}$ & $\begin{array}{c}2 \\
(1.9 \%)\end{array}$ & $\begin{array}{c}1 \\
(1.2 \%)\end{array}$ & 0.582 & $\begin{array}{c}2.58 \\
(0.16-76.86)\end{array}$ & $\begin{array}{c}1.52 \\
(0.27-2.34)\end{array}$ \\
\hline $\begin{array}{l}\text { FLG mutation (+) } \\
\text { rs6693927 AG + AA }\end{array}$ & $\begin{array}{c}12 \\
(11.7 \%)\end{array}$ & $\begin{array}{c}1 \\
(1.2 \%)\end{array}$ & 0.002 & $\begin{array}{c}15.50 \\
(1.84-341.5)\end{array}$ & $\begin{array}{c}2.11 \\
(1.29-2.37)\end{array}$ \\
\hline
\end{tabular}

Measure of interaction on additive scale: $R E R I=12.31 ; A P=0.79 ; S=6.62$. Measure of interaction on multiplicative scale: ratio of ORs $=3.73$.

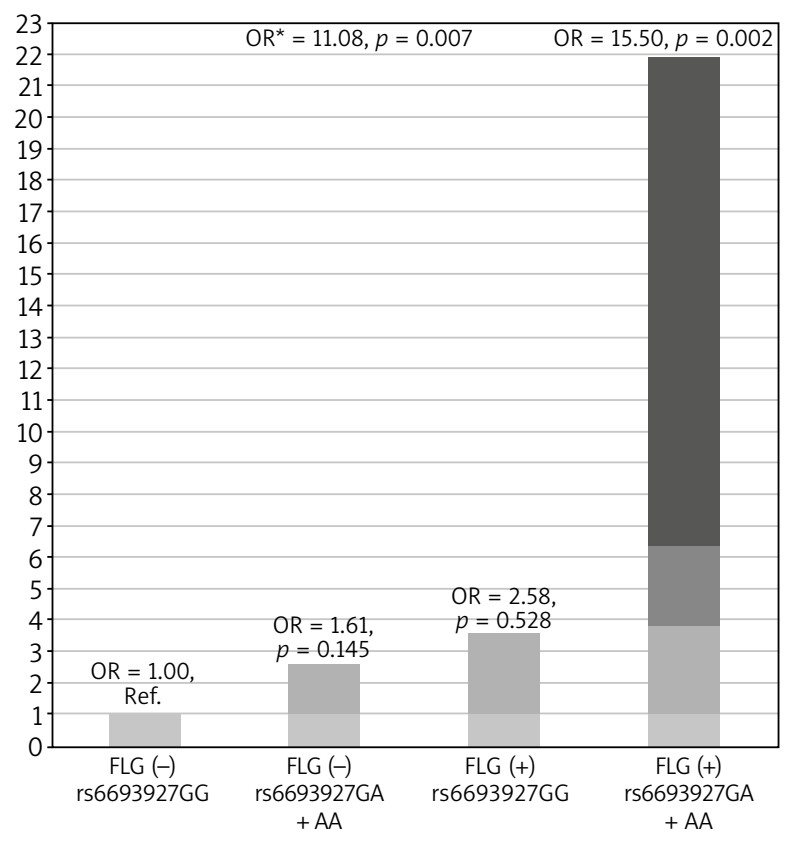

Interactive effect Individual effect of rs6693927 (GA + AA) Individual effect of FLG (+) Background

Figure 1. Interaction between SPRR2B rs6693927 and the FLG mutations in atopic eczema

$=0.828$ ), which may be because of the low sample size in our study and insufficient statistical power.

Finally, we evaluated the association between the tested risk variant and the presence of other atopic phenotypes such as allergic sensitisation, asthma, allergic rhinitis and eczema-associated asthma. In the overall study population, the rs6693927 SNP did not significantly increase the risk of asthma. However, we revealed that the risk allele predisposed to eczema-associated asthma, increasing the risk of this combined phenotype more than 5 -fold. In contrast, in the absence of eczema, the association with asthma was not significant. When we then evaluated the rs6693927 SNP as a risk factor for asthma in the subgroup of children with eczema, we could not find an independent effect of rs6693927 on asthma.
We did not find an independent effect of rs6693927 SNP on allergic sensitisation and allergic rhinitis in the overall study population and after stratification according to the presence or absence of eczema (Table 4).

\section{Discussion}

Atopic eczema (AE) is a common inflammatory disease caused by a combination of genetic and environmental factors [5]. The FLG mutations remain the most significant and widely replicated genetic risk factor for $\mathrm{AE}$ reported to date [10-12, 35, 36]. These results were also confirmed in our former studies [31, 32] and other study conducted in Polish AE cohorts, which revealed that the FLG mutation, alone and in combination with certain IL-10 or IL-13 polymorphisms, enhances the risk of the development of AE [37]. This is in line with observations that FLG mutations alone are unlikely to account for the total burden of AE at a population level [7, 21, 22, 36, 38]. Recent GWASs for AE have identified an additional association signal in the EDC genes on chromosome 1q21 apart from the mutations in the FLG gene [20, 23, 38-41]. SPRRs, the precursor proteins of CE encoded on the EDC region, are linkers for transglutaminase-mediated protein crossbridging and play a structural role in all stages of CE formation [25, 42-44]. The experimental studies demonstrated dysregulation in SPRR gene expression accompanied by an altered pattern in the composition of SPRR proteins in patients with $\mathrm{AE}[22,45,46]$. In systematic screening for putatively deleterious mutations in the EDC, Marenholz et al. identified an rs28989168 SPRR3 variant that carried an extra 24-bp repeat in the central domain as a previously unreported risk factor for $A E$ [28]. In our study we focused on another SPRR family gene, i.e., the SPRR2B gene, which had previously been found to exhibit changes in expression in inflammatory skin disease and the expression of which is believed to be of major importance for CE biomechanical properties [47-49]. We provided evidence for the highly significant association of rs6693927[A] allele in SPRR2B with $A E$ in the non-allergic group. A weak trend towards an association was also seen in the overall study population. 
Table 4. Associations between SPRR2B rs6693927 genotype and allergic diseases. The control group comprises all individuals, who do not belong to any of the disease group

\begin{tabular}{lccccc}
\hline Genotype & \multirow{2}{*}{$\begin{array}{c}\text { Total } \\
n\end{array}$} & $n(\%)$ & \multicolumn{3}{c}{ rs6693927 genotype status } \\
\cline { 5 - 6 } & & GG (\%) & AG + AA (\%) & $P$-value & OR (95\% Cl) \\
\hline Allergic sensitisation & $66 / 188(35.1 \%)$ & $21 / 58(36.2 \%)$ & $45 / 130(34.6 \%)$ & 0.836 & $0.93(0.46-1.87)$ \\
\hline Polysensitisation (Sepc. IgE > 1) & $19 / 188(10.1 \%)$ & $6 / 58(10.3 \%)$ & $13 / 130(10.0 \%)$ & 0.942 & $0.96(0.32-2.67)$ \\
\hline Allergic sensitisation in subjects with eczema & $55 / 103(53.4 \%)$ & $18 / 26(69.2 \%)$ & $37 / 77(48.05 \%)$ & 0.467 & $1.32(0.64-2.75)$ \\
\hline Allergic sensitisation in subjects without eczema & $11 / 85(12.9 \%)$ & $3 / 32(9.37 \%)$ & $8 / 53(15.1 \%)$ & 0.524 & $1.72(0.42-7.01)$ \\
\hline Asthma & $28 / 188(14.9 \%)$ & $5 / 58(8.62 \%)$ & $23 / 130(17.7 \%)$ & 0.124 & $2.28(0.82-6.33)$ \\
\hline Eczema plus asthma & $20 / 188(10.6 \%)$ & $2 / 58(3.45 \%)$ & $18 / 130(13.8 \%)$ & 0.029 & $5.44(1.17-25.16)$ \\
\hline Eczema without asthma & $83 / 188(44.1 \%)$ & $24 / 58(44.4 \%)$ & $59 / 130(45.4 \%)$ & 0.313 & $1.48(0.76-2.87)$ \\
\hline Asthma without eczema & $8 / 188(4.2 \%)$ & $3 / 58(5.2 \%)$ & $5 / 130(3.8 \%)$ & 1.000 & $1.01(0.22-4.53)$ \\
\hline Eczema plus asthma vs. eczema without asthma & $20 / 103(19.4 \%)$ & $2 / 26(7.7 \%)$ & $18 / 77(23.4 \%)$ & 0.093 & $3.66(0.78-17.01)$ \\
\hline Allergic rhinitis & $35 / 188(18.6 \%)$ & $12 / 58(20.9 \%)$ & $23 / 130(17.7 \%)$ & 0.686 & $0.82(0.39-1.79)$ \\
\hline Eczema plus allergic rhinitis & $24 / 188(12.8 \%)$ & $10 / 58(17.2 \%)$ & $14 / 130(10.8 \%)$ & 0.950 & $1.00(0.37-2.43)$ \\
\hline Eczema without allergic rhinitis & $79 / 188(42.0 \%)$ & $16 / 58(27.6 \%)$ & $63 / 130(48.5 \%)$ & 0.008 & $2.68(1.31-5.51)$ \\
\hline Allergic rhinitis without eczema & $11 / 188(5.85 \%)$ & $2 / 58(3.4 \%)$ & $9 / 130(6.9 \%)$ & 0.196 & $3.06(0.62-15.21)$ \\
\hline
\end{tabular}

Similarly, Epstein et al. demonstrated a possible association between an rs6693927 SNP in SPRR2B and eczema in the CCAAPS (Cincinnati Childhood Allergy \& Air Pollution Study) cohort; however, this finding was not statistically significant [29]. The SPRR2B gene is expressed predominantly in squamous epithelium where it plays an important role in the formation of the insoluble keratinocyte-cornified crosslinked envelope essential for structural integrity and permeability $[26,48]$. Accordingly, our results support the hypothesis that SPRR2B variants may influence skin barrier function by altering the physical properties of the CE and thus may contribute to AE susceptibility, confirming the key role of the epidermal barrier in AE development. Interestingly, our study revealed a strong effect of the rs6693927[A] allele on the non-allergic form of $A E$, whereas there was no effect in the presence of allergic sensitisation. In addition, we demonstrated that allergic sensitisation per se was not associated with the risk allele both in the overall study population and in a subgroup with AE, indicating that IgE-mediated hypersensitivity is not the primary disease manifestation of the risk variant in SPRR2B. It is worth pointing out that the effect of rs6693927 SNP on the AE risk was independent of the well-established FLG null mutations, confirming that other genes located within the EDC, such as SPRR2B, are involved in the pathogenesis of $A E$ and may play an essential role in disease development. Moreover, our results suggest some possible positive interaction on the additive or multiplicative scale between rs6693927 SNP and FLG mutations because the combined disease risk of the both tested variants was significantly higher than that observed for these alleles separately. The interactive effect of SPRR2B and FLG variants is biologically plausible due to the high degree of relationship among the EDC genes, their coordinated expression, as well as the interaction of the encoded proteins in the formation of the epidermis [28, 42].

$A E$ is often the first manifestation of atopic march in early life and often predates the development of allergic airway disease [2]. Based on the assumption that this progression from $A E$ to secondary respiratory allergies is likely to be due to the defective epidermal barrier function, the EDC genes could be predicted to play an important role in asthma development [14-19]. This in particular may apply to the SPRR2B gene due to the potential involvement of SPRR2B proteins in the pathophysiology of allergic responses in diverse mucosal tissues [26]. In our study the compound phenotype of asthma concomitant with eczema has shown a strong, statistically significant association with the rs6693927 risk variant. This is consistent with the study in the CCAAPS birth cohort, which reported that the SPRR2B risk variant is associated with the eczema plus asthma phenotype [29]. Further analysis of the combined allergic phenotypes revealed that the rs6693927 risk variant was associated with asthma only in the context of eczema emphasising an essential role of eczema in the allergic airways disease associated with the rs6693927 risk variant. These results suggest that SPRR2B might predispose to the genetically distinct form of asthma or a particular asthma phenotype occurring in the context of eczema, in contrast to the form of asthma not linked with eczema. However, the mechanism of the asthma risk associated with the SPRR2B variant is not yet fully understood; this may be associated with changes in the biomechanical properties of CE, subsequent skin barrier impairment and percutaneous allergic sensitisation [47-51]. On the 
other hand SPRR2 expression is not restricted to squamous epithelium [42]. In particular SPRR2B is expressed in lungs of mice, and its expression is specifically altered in the nasal epithelium of asthmatic patients [26, 49, 52]. In situ hybridisation revealed marked allergen-induced expression of SPRR2B in the asthmatic lung, which was observed in a subset of airway epithelial and mononuclear cells associated with allergic inflammation [26]. It has been speculated that allergic lung response that involves epithelial injury and repair may be mediated by the altered expression on the SPRR2 gene as part of a stresS response to infection or allergic inflammation signals $[26,49,53]$. These observations raise the possibility that SPRR2B may play an important role in the pathogenesis of the distinct phenotype eczema-associated asthma.

A potential limitation of our study, typical of all casecontrol studies, is the relatively small sample size and, as a consequence, rather low statistical power, which may lead to false negative or false positive results. Nevertheless, we were able to demonstrate statistically significant and biologically plausible effects. An interaction analysis requires a large population, so our results should be interpreted carefully; there was some evidence of interactions on an additive scale, but there was insufficient statistical power to either confirm or refute these findings.

\section{Conclusions}

Our results indicate that the rs6693927 risk variant in the SPRR2B gene may contribute to AE susceptibility, and this effect seems to be independent of the wellestablished FLG risk alleles, confirming that other genes located within the EDC are involved in the pathogenesis of AE. Moreover, we identified the association of that rs6693927 risk variant with eczema-associated asthma, suggesting that genetically determined impairment of the skin barrier is critical for the development not only of $A E$, but also for particular asthma phenotype occurring in the context of eczema. In addition, our results revealed that the rs6693927[A] variant and FLG mutations are candidate genes that may control the risk of $A E$ in an interactive manner. We conclude that future studies on $\mathrm{AE}$ have to consider gene-gene interaction, as each genetic variant may have their own effect in isolation but the combination of functional SNPs in more than one gene may magnify their impact on the disease.

\section{Acknowledgments}

The presented study was carried out as part of the research project of the Wroclaw Medical University, number SUB.A220.20.043 according to the records in Simple System. Publication costs were covered by research project number SUB.C260.21.011 according to the records in Simple System.

\section{Conflict of interest}

The authors declare no conflict of interest.

\section{References}

1. Schultz Larsen F, Hanifin J. Epidemiology of atopic dermatitis. Immunol Allergy Clin North Am 2002; 22: 1-24.

2. Sprengler JM, Paller AS. Atopic dermatitis and the atopic march. J Allergy Clin Immunol 2003; 112: S1:18-7.

3. von Kobyletzki LB, Bornehag CG, Hasselgren M, et al. Eczema in early childhood is strongly associated with the development of asthma and rhinitis in a prospective cohort. BMC Dermatol 2012; 12: 11.

4. Baltardini M, Bergstrom A, Bohme M, et al. Infantile eczema prognosis and risk of asthma and rhinitis in preadolescence. J Allergy Clin Immunol 2014; 133: 594-6.

5. Brown SJ, McLean SWH. Eczema genetics: current state of knowledge and future goals. J Invest Dermatol 2009; 129: 543-52.

6. Kiyohara C, Tanaka K, Myiake Y. Genetic susceptibility to atopic dermatitis. Allergol Int 2008; 57: 39-56.

7. Palmer CN, Irvine AD, Terron-Kwiatkowski A, et al. Common loss-of-function variants of epidermal barrier protein filaggrin are a major predisposing factor for atopic dermatitis. Nat Genet 2006; 38: 441-6.

8. Irvine AD, McLean WH, Leung DY. Filaggrin mutations associated with skin and allergic diseases. N Engl J Med 2011; 365: 1315-27.

9. Brown SJ, McLean WH. One remarkable molecule: filaggrin. J Invest Dermatol 2012; 132: 650-4.

10. van den Oord RA, Sheikh A. Filaggrin gene defects and risk of developing allergic sensitisation and allergic disorders: systematic review and meta-analysis. BMJ 2009; 339: b2433.

11. Rodriguez E, Baurecht H, Herberich E, et al. Meta-analysis of filaggrin polymorphisms in eczema and asthma: robust risk factors in atopic dermatitis. J Allergy Clin Immunol 2009; 123: 1361-70.

12. Henderson J, Northstone K, Lee SP, et al. The burden of disease associated with filaggrin mutations: a populationbased, longitudinal birth cohort study. J Allergy Clin Immunol 2008; 121: 872-7.

13. Weidinger S, O Sullivan M, Illig T, et al. Filaggrin mutations, atopic eczema, hay fever, and asthma in children. J Allergy Clin Immunol 2008; 121: 1203-9.

14. Bantz SK, Zhu Z, Zheng T. The atopic march: progression from atopic dermatitis to allergic rhinitis and asthma. J Clin Cell Immunol 2014; 5: 202-17.

15. Kelleher MM, Dunn-Galvin A, Grey C, et al. Skin barrier impairment at birth predicts food allergy at 2 years of age. J Allergy Clin Immunol 2016; 137: 1111-6.

16. Agrawal R, Woodfolk JA. Skin barrier defects in atopic dermatitis. Curr Allergy Asthma Respir 2014; 14: 433-9.

17. Egawa G, Kabashima K. Multifactorial skin barrier deficiency and atopic dermatitis: Essential topics to prevent the atopic march. J Allergy Clin Immunol 2016; 138: 350-8.

18. Elias PM, Wakefield J. Mechanisms of abnormal lamellar body secretion and the dysfunctional skin barrier in atopic dermatitis. J Allergy Clin Immunol 2014; 134: 781-91.

19. Kubo A, Nagao K, Amagai M. Epidermal barrier dysfunction and cutaneous sensitization in atopic diseases. J Clin Invest 2012; 122: 440-7. 
20. Tamari M, Hirota T. Genome-wide association studies of atopic dermatitis. J Dermatol 2014; 41: 213-20.

21. Paternoster L, Standl M, Chen CM, et al. Meta-analysis of genome-wide association studies identifies three new risk loci for atopic dermatitis. Nat Genet 2012; 44: 187-92.

22. Sugiura $\mathrm{H}$, Ebise $\mathrm{H}$, Tazawa T, et al. Large-scale DNA microarray analysis of atopic skin lesions shows overexpression of an epidermal differentiation gene cluster in the alternative pathway and lack of protective gene expression in the cornified envelope. Br J Dermatol 2005; 152: 146-9.

23. Esparza-Gordillo J, Wedinger S, Folster-Holst R, et al. A common variant on chromosome 11q13 is associated with atopic dermatitis. J Invest Dermatol 2009; 131: 982-4.

24. Guttman-Yassky E, Suarez-Farinas M, Chiricozzi A, et al. Broad defects in epidermal cornification in atopic dermatitis identified through genomic analysis. J Allergy Clin Immunol 2009; 124: 1235-44.

25. Steinert PM, Candi E, Katasova T, et al. Small proline-rich proteins are cross-bridging proteins in the cornified cell envelopes of stratified squamous epithelia. J Struct Biol 1998; 122: 76-85.

26. Zimmermann N, Doepker MP, Witte DP, et al. Expression and regulation of small proline-rich protein 2 in allergic inflammation. Am J Respir Cell Moll Biol 2005; 32: 428-35.

27. Kelsell DP, Byrne C. SNPing at the epidermal barier. J Invest Dermatol 2011; 131: 1593-5.

28. Marenholz I, Gimenez Rivera VA, Esparza-Gordillo J, et al. Association screening in the epidermal differentiation complex (EDC) identifies an SPRR3 repeat number variant as a risk factor for eczema. J Invest Dermatol 2011; 131: 1644-9.

29. Epstein TG, LeMasters GK, Bernstein DI, et al. Genetic variation in small proline-rich protein $2 \mathrm{~B}$ as a predictor for asthma among children with eczema. Ann Allergy Asthma Immunol 2012; 108: 145-50.

30. Hanifin JM, Rajka G. Diagnostic featrures of atopic dermatitis. Acta Derm Venerol Suppl 1980; 92: 44-7.

31. Dębińska A, Danielewicz H, Drabik-Chamerska A, et al. Filaggrin loss-of-function mutations predispose to atopic dermatitis and allergic sensitisation in Polish children population Allergy 2015; 70 (suppl. 101): 533. European Academy of Allergy and Clinical Immunology Congress. Barcelona (Spain), 6-10 June 2015. Abstracts.

32. Dębińska A, Danielewicz H, Drabik-Chamerska A, et al. Filaggrin loss-of-function mutations as a predictor for atopic eczema, allergic sensitization and eczema-associated asthma in Polish children population. Adv Clin Exp Med 2017; 26: 991-8.

33. Knoll MJ, VanderWeele TJ, Groenwold RH, et al. Estimating measures of interaction on an additive scale for preventive exposure. Eur J Epidemiol 2011; 26: 433-8.

34. Knoll MJ, VanderWeele TJ. Recommendation for presenting analyses of effect modification and interaction. Int J Epidemiol 2012; 41: 514-20.

35. Baurecht H, Irvine AD, Novak N, et al. Toward a major risk factor for atopic dermatitis: meta-analysis of filaggrin polymorphism data. J Allergy Clin Immunol 2007; 120: 1406-12.

36. Marenholz I, Nickel R, Ruschendorf F, et al. Filaggrin loss-offunction mutations predispose to phenotypes involved in the atopic march. J Allergy Clin Immunol 2006; 118: 866-71.

37. Lesiak A, Kuna P, Zakrzewski M, et al. Combined occurrence of filaggrin mutations and IL-10 or IL-13 polymorphisms predisposes to atopic dermatitis. Exp Dermatol 2011; 20: 491-5.
38. Zaniboni MC, Orfali RL. Skin barrier in atopic dermatitis: beyond filaggrin. An Bras Dermatol 2016; 91: 472-8.

39. Sun LD, Xiao FL, Li Y, et al. Genome-wide association study identifies two new susceptibility loci for atopic dermatitis in the Chinese Han population. Nat Genet 2011; 43: 690-4.

40. Paternoster L, Standl M, Chen CM, et al. Meta-analysis of genome-wide association studies identifies three new risk loci for atopic dermatitis. Nat Genet 2012; 44: 187-92.

41. Ferreira MAR, Vonk JM, Baurecht $\mathrm{H}$, et al. Eleven loci with new reproducible genetic association with allergic disease risk. J Allergy Clin Immunol 2019; 143: 691-9.

42. Kypriotou M, Huber M, Hohl D. The human epidermal differentiation complex: cornified envelope precursors, S100 proteins and the 'fused genes' family. Exp Dermatol 2012; 21: 643-9.

43. Tesfaigizi J, Carlson DM. Expression, regulation and function of the SPR family of proteins. Cell Biochem Biophys 1999; 30: $243-65$

44. Hohl D, de Viragh PA, Amiguet-Barras F, et al. The small proline-rich proteins constitute a multigene family of differentially regulated cornified cell envelope processor proteins. J Invest Dermatol 1995; 104: 902-9.

45. Jarzab J, Filipowska B, Zebracka J, et al. Locus 1q21 gene expression changes in atopic dermatitis skin lesions: dysregulation of small proline-rich region 1A. Int Arch Allergy Immunol 2010; 151: 28-37.

46. Trzeciak M, Sakowicz-Burkiewicz M, Wesserling M, et al. Expression of cornified envelope proteins in skin and its relationship with atopic dermatitis phenotype. Acta Derm Venerol 2017; 97: 36-41.

47. De Heller-Milev M, Huber M, Panizzon R, Hohl D. Expression of small proline-rich proteins in neoplasmatic and inflammatory skin diseases. Br J Dermatol 2000; 143: 733-40.

48. Cabral A, Voskamp P, Clenton-Jansen AM, et al. Structural organization and regulation of the small proline-rich family of cornified envelope precursors suggest a role in adaptive barrier function. J Biol Chem 2001; 276: 19231-7.

49. Segre JA. Epidermal barrier formation and recovery in skin disorders. J Clin Invest 2006; 116: 1150-8.

50. McAleer MA, Irvine AD. The multifactorial role of filaggrin in allergic skin disease. J Allergy Clin Immunol 2013; 131: 280-91.

51. De Benedetto A, Kubo A, Beck LA. Skin barrier disruption: a requirement for allergen sensitization? J Invest Dermatol 2008; 132: 949-63.

52. Finkelman FD, Yang M, Perkins C, et al. Suppressive effect of IL-4 on IL-13 induced genes in mouse lung. I Immunol 2005; 174: 4630-8.

53. Tesfaigzi J, Thng J, Hotchkiss JA, et al. A small proline-rich protein, SPRR1, is upregulated early during tobacco smoke-induced squamous metaplasia in rat nasal epithelia. Am J Respir Cell Mol Biol 1996; 228: 277-82. 